\title{
Commentary: Why the Y-graft?
}

\author{
Steven M. Schwartz, MD, MS, FRCPC, FAHA
}

\author{
From the Divisions of Cardiac Critical Care Medicine and Cardiology, Departments of Paediatrics and Critical \\ Care Medicine, The Hospital for Sick Children and The University of Toronto, Toronto, Ontario, Canada. \\ Disclosures: Author has nothing to disclose with regard to commercial support. \\ Received for publication Aug 5, 2019; accepted for publication Aug 6, 2019; available ahead of print Oct 5, 2019. \\ Address for reprints: Steven M. Schwartz, MD, MS, FRCPC, FAHA, Department of Critical Care Medicine, The \\ Hospital for Sick Children, 555 University Ave, Toronto, ON M5G 1X8, Canada (E-mail: steven.schwartz@ \\ sickkids.ca). \\ J Thorac Cardiovasc Surg 2020;159:665-6 \\ $0022-5223 / \$ 36.00$ \\ Copyright (C) 2019 by The American Association for Thoracic Surgery \\ https://doi.org/10.1016/j.jtcvs.2019.08.053
}

Long-term outcomes after the Fontan operation for single-ventricle lesions remain suboptimal, with many patients having complications related to resistance through the Fontan circuit or maldistribution of hepatic blood flow between the lungs. These mechanisms of Fontan failure have persisted through various iterations of Fontan anatomy that have been developed during the almost 5 decades since the first successful atriopulmonary connection in 1971. A recent modification to the Fontan operation is the use of a bifurcated Y-graft to complete the inferior cavopulmonary connection. The Y-graft offers a theoretic advantage of better right-left distribution of hepatic distribution of blood flow (HDBF), which contains the stillelusive "hepatic factor" responsible for suppression of pulmonary arteriovenous malformations, even at the expense of potentially greater overall resistance of the Fontan circuit as a result of the bifurcation and caliber change of the Y-graft. Although in vitro testing suggests that, on balance, the Y-graft Fontan might have overall benefit, ${ }^{1}$ there have been very few data published on patient outcomes.

In this issue of The Journal of Thoracic and Cardiovascular Surgery, Trusty and colleagues ${ }^{2}$ report intermediateterm outcomes of 10 patients after a Y-graft Fontan procedure. They previously reported short-term data from magnetic resonance imaging that was somewhat discouraging in terms of $\mathrm{HDBF}$, as well as overall resistance through the Fontan circuit. ${ }^{3}$ The interesting finding of their current report is that there was improvement in these outcomes at an average of 3 years after surgery. The patients with Y-grafts were compared with 3 different cohorts of patients who had undergone extracardiac conduit placement at averages of less than 3 years, 3 to 6 years, and 10 years previously. This somewhat novel approach to finding comparison groups was necessitated by the lack of an extracardiac conduit cohort with a follow-up time matched to the Y-graft cohort. The patients with Y-grafts at 3 years showed a tendency toward better HDBF and no real difference in overall

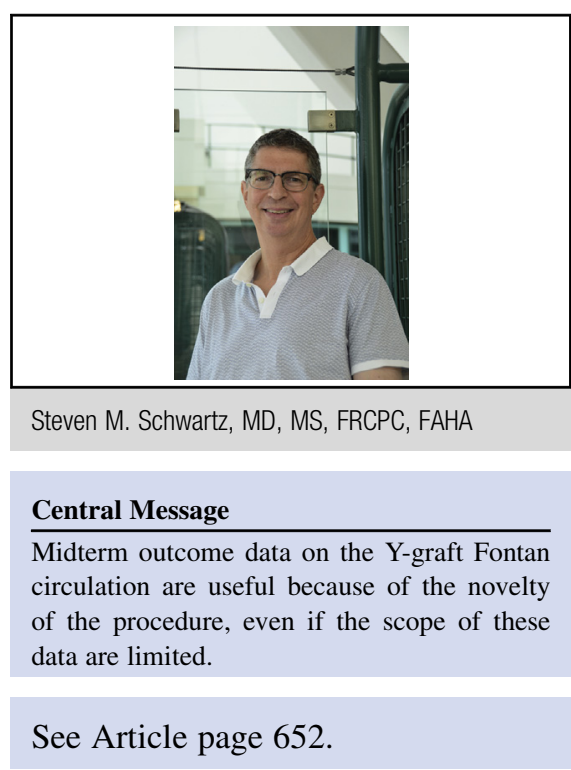

resistance relative to the extracardiac conduit groups. The use of this type of "control" group has serious and obvious limitations, both from the introduction of the limitations of historical controls and from problems caused by different lengths of follow-up. Furthermore, the cohort of patients with Y-grafts is small $(\mathrm{n}=10)$ and from a single institution. Nevertheless, this represents the largest cohort to date, and in the face of emerging clinical practice, some data are better than no data. Furthermore, the data on the change in HDBF and total cavopulmonary resistance within the Ygraft cohort are consistent enough to be potentially informative. Overall, 9 of 10 patients had an improvement in HDBF, and 8 of 10 had an improvement in overall resistance.

There is no doubt that the pediatric cardiac community will continue to search for ways to improve the mechanics of the Fontan circulation, as the growing number of adult post-Fontan patients with complications becomes a more and more significant problem for our field, our patients, and their families. Studies such as that of Trusty and colleagues, ${ }^{2}$ in which institutions carefully examine the outcomes of their innovative practices, are useful, albeit limited, for informing further studies and clinical progress.

\section{References}

1. Marsden AL, Bernstein AJ, Reddy VM, Shadden SC, Spilker RL, Chan FP, et al. Evaluation of a novel Y-shaped extracardiac Fontan baffle using computational fluid dynamics. J Thorac Cardiovasc Surg. 2009;137:394-403.e2. 
2. Trusty PM, Wei Z, Sales M, Kanter KR, Fogel MA, Yoganathan AP, et al. Y-graft modification to the Fontan procedure: increasingly balanced flow over time. J Thorac Cardiovasc Surg. 2020;159: 652-61.
3. Trusty PM, Restrepo M, Kanter KR, Yoganathan AP, Fogel MA, Slesnick TC. A pulsatile hemodynamic evaluation of the commercially available bifurcated Ygraft Fontan modification and comparison with the lateral tunnel and extracardiac conduits. J Thorac Cardiovasc Surg. 2016;151:1529-36. 